\title{
Optimasi Jumlah Produksi Roti Menggunakan Program Linear Dan Software POM-QM
}

\author{
Matheus Supriyanto Rumetna ${ }^{1}$, Tirsa Ninia Lina ${ }^{2}$, Titin Puspita Sari ${ }^{3}$, \\ Piton Mugu $^{4}$, Adrianus Assem ${ }^{5}$, Richard Sianturi ${ }^{6}$ \\ Program Studi Sistem Informasi, Universitas Victory Sorong, Indonesia.
}

\section{INFORMASI ARTIKEL}

Diterima Redaksi: 2 Februari 2021

Diterbitkan Online: 24 Maret 2021

\section{KATA KUNCI}

Linear Programming, Simplex

Method, Product Optimization, POM$Q M$

\section{KORESPONDENSI}

\section{E-mail:}

matheus.rumetna@gmail.com

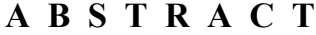

Dani Bakery factory is a factory that is engaged in non-service business, which is located at Aimas Unit 1, Sorong Regency, West Papua Province. In the midst of increasingly fierce and difficult business competition, especially when hit by the current pandemic conditions, it causes problems in determining the amount of production for a month in order to maximize profits. This study aims to solve these problems using a Linear Program, and to be more effective and efficient, Information Technology in the form of POM-QM software is used. The methods used for data collection were observation and interviews, while for data analysis using the simplex method and POMQM software. The result is that the Dani Bakery factory gets a profit of 200,000,000 IDR per bread production every month, from which this result can be used as a reference in making decisions.
\end{abstract}

\section{Latar Belakang}

Saat ini persaingan bisnis makin ketat dan sulit, apalagi diterpa kondisi pandemi. Kondisi ini menyebabkan banyak perusahaan yang mengalami kesulitan operasionalnya [1]. Kreatifitas sangat dibutuhkan agar perusahaan dapat berjalan atau menjadi yang terdepan dalam bidangnya [2],[3]. Oleh karena itu, setiap perusahaan harus mengembangkan dan meningkatkan kinerja agar dapat mencapai efektivitas dan efisiensi [4],[5]. Setiap orang atau pengusaha juga harus dapat mencari kesempatan yang ada untuk dapat bersaing dalam bisnis ataupun industri dengan melihat peluang yang ada dilingkungan sekitarnya [6].

Perkembangan Teknologi Informasi (TI) merupakan salah satu peluang yang dapat dimanfaatkan oleh perusahaan atau badan usaha.
Banyak teknologi yang dapat digunakan untuk meningkatkan efektifitas dan efisiensi usaha. Terdapat berbagai jenis TI dan sangat mudah untuk didapatkan serta digunakan, tergantung kemauan dan kemampuan pengusaha.

Pabrik Dani Bakery merupakan salah satu pabrik yang bergerak dalam bidang usaha non jasa yang beralamat di Aimas Unit 1, Jalan Cempedak RT.023/008, Kelurahan Malawili, Distrik Aimas, Kabupaten Sorong, Provinsi Papua Barat. Untuk menjalankan dan mengembangkan usaha produksi roti diperlukan langkah-langkah untuk dapat mengalokasikan bahan baku serta meningkatkan keuntunngan (laba).

Seiring dengan perkembangan waktu, usaha inipun mengalami masalah dalam menentukan jumlah produksi untuk sebulan agar dapat 
menghasilkan keuntungan yang maksimal. Terdapat banyak cara untuk mengatasi masalah tersebut, salah satunya dengan menggunakan Program Linear (PL) [7],[8]. PL merupakan teknik optimasi untuk menemukan nilai optimum dari suatu pengambilan keputusan. Terdapat tiga elemen penting dalam PL yaitu variabel keputusan, fungsi tujuan, dan pembatas (constraints) [9],[10],[11],[12],[13].

Metode Simpleks adalah bagian dari PL [14]. Metode Simpleks ini merupakan metode yang umum digunakan untuk menyelesaikan seluruh masalah PL, baik yang melibatkan dua variabel keputusan maupun lebih dari dua variabel keputusan [15],[16],[17],[18]. Metode inipun efektif dalam menentukan jumlah produksi demi menghasilkan keuntungan yang optimum dari sebuah usaha atau perusahaan [19],[20].

Agar lebih efisien dalam menyelesaikan masalah yang dialami oleh Pabrik Dani Bakery, selain menggunakan Metode Simpleks pemanfaatan TI dalam hal ini menggunakan software POM-QM menjadi penting, karena selain cepat dalam melakukan perhitungan, hasil perhitungannyapun tepat.

\section{Kajian Literatur}

2.1 Program Linier

PL merupakan bagian dari Riset Operasional (RO) [7],[8],[16]. Metode atau teknik untuk menentukan nilai atau hasil optimum dari suatu persoalan linear atau yang lebih dikenal dengan PL. Hasil yang diperoleh dalam suatu himpunan penyelesaian persoalan linier hanya dua yaitu maksimal atau minimal [17],[18].

RO adalah proses pencarian cara untuk menentukan tindakan yang terbaik atau optimal dari suatu pengambilan keputusan dalam situasi sumber-sumber daya yang terbatas. Syarat untuk memaksimumkan keuntungan dibagi menjadi dua cara yaitu membandingkan hasil penjualan total dengan biaya total [9].

\subsection{Metode Simpleks}

George Dantzig pada 1946 mengembangkan metode ini dan sangat cocok dengan era komputerisasi kini [21]. Kemudian pada tahun yang sama di Bell Laboratories seorang bernama Narendra Karmarkar menciptakan sebuah teknik untuk memecahkan masalah PL yang lebih kompleks, sehingga cara kerja serta hasil dari metode ini menjadi lebih baik. Cara kerja metode ini adalah melakukan perhitungan secata iterasi yaitu langkah perhitungan yang sama namun diulang hingga mencapai solusi yang optimum [22].

Langkah perhitungan metode Simpleks adalah sebagai berikut [23],[24],[25]:

1) Mengubah fungsi tujuan dengan batasan, kemudian fungsi ini dijadikan fungsi implisit. Contoh $\mathrm{Z}=70 \mathrm{X} 1+70 \mathrm{X} 2$ menjadi $\mathrm{Z}-70 \mathrm{X} 1-70 \mathrm{X} 2$, kemudian membuat tabel simpleks berdasarkan data yang ada.

2) Memilih kolom kunci (kolom yang bernilai negatif tertinggi).

3) Memilih baris kunci (baris yang nilai indexnya sangat rendah). Rumusnya:

Index = nilai kanan/nilai kolom kunci

4) Mengubah nilai-nilai baris kunci dengan cara membagi dengan angka kunci.

5) Mengubah nilai-nilai selain pada baris kunci. Rumusnya:

Baris baru $=$ baris lama -

(koefisien angka kolom kunci*nilai baris baru kunci)

6) Melakukan revisi hingga baris $Z$ tidak mengandung nilai negatif, caranya dengan mengulangi langkah ke 2 hingga ke 5 .

\subsection{Software POM-QM}

POM-QM merupakan aplikasi komputer yang hadir untuk menyelesaiakan masalah bersifat kuantitatif pada bidang produksi serta menejemen operasi [26],[27]. Salah satu manfaat besar yang dirasakan yaitu software ini menjadi alternatif aplikasi yang membantu dalam pengambilan keputusan [28],[29]. Contohnya untuk menentukan kombinasi produksi yang sesuai agar menghasilkan keuntungan yang optimal. Menentukan pengorderan barang agar biaya maintanance menjadi minimal, penentuan tugas karyawan terhadap pekerjaan, dan sebagainya.

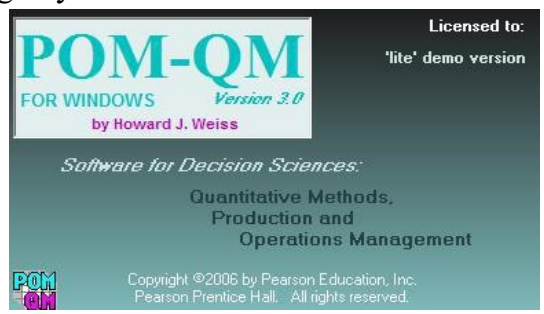

Gambar 1. Tampilan Awal Software POM-QM 
Software ini sangat mudah digunakan dan memiliki tampilan yang menarik [26]. Terdapat berbagai modul dalam software ini yang membantu dalam penyelesaian masalah. Adapun modul tersebut terdiri dari:

1) Aggregate Planning

2) Assigment (Penugasan)

3) Balancing Assembly Line

4) Break even / Cost-Volume Analysis

5) Decision Analysis

6) Forecasting

7) Inventory

8) Job Shop Scheduling

9) Learning Curve

10) Linier Programming (Pemrograman Linear)

11) Location

12) Lot Sizing

13) Material Requirement Planning

14) Operations Lay Out

15) $P E R T / C P M$

16) Quality Control

17) Realibility

18) Simulati

19) Transportation (masalah transportasi)

20) Waiting Lines

\section{Metodologi}

3.1 Metode Pengumpulan Data

Pengumpulan data dilakukan menggunakan dua cara, yaitu

[30],[31],[32],[33],[34],[35],[36],[37]:

1) Studi lapangan (observasi), dimana observasi dilakukan untuk melihat secara langsung proses yang terjadi di Pabrik Dani Bakery.

2) Wawancara, hal ini dilakukan dengan salah satu pimpinan Pabrik Dani Bakery yaitu bapak Tajidin.

Observasi dan wawancara ini menghasilkan data bahan baku, produksi yang dihasilkan, jumlah produksi serta keuntungan per bulan dari masing-masing jenis produk.

\subsection{Metode Analisis Data}

Data yang telah dikumpulkan akan dianalisis menggunakan metode Simpleks serta software POM-QM, sehingga mendapatkan hasil yang tepat [7],[12],[26].

Proses ini dapat dilihat secara rinci berdasarkan alur penelitian yang terdapat pada Gambar 2.

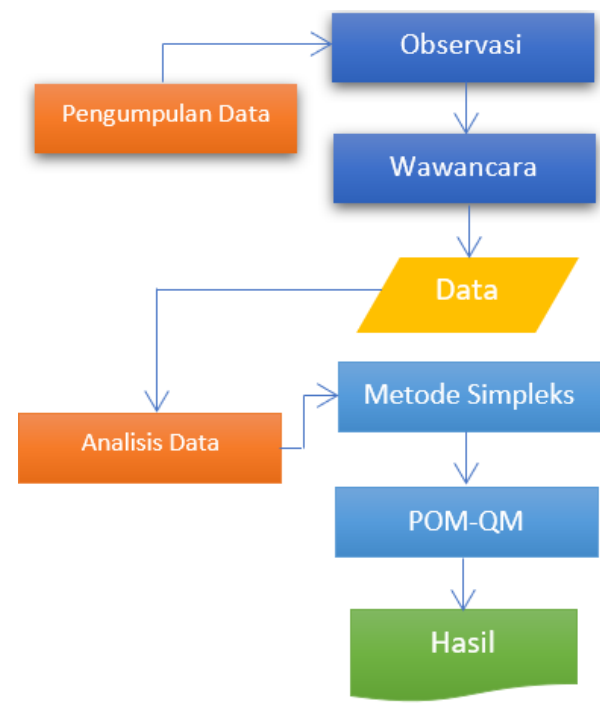

Gambar 2. Alur Penelitian

\section{Pembahasan}

Pabrik Dani Bakery memproduksi 3 jenis roti yaitu roti tawar, roti manis, dan roti sisir. Dalam memproduksi roti tawar memerlukan bahan $10 \mathrm{~kg}$ tepung terigu, $2 \mathrm{~kg}$ mentega, $5 \mathrm{ram}$ telur, $10 \mathrm{~kg}$ gula pasir. Setiap produksi roti manis memerlukan bahan $4 \mathrm{~kg}$ tepung terigu, $2 \mathrm{~kg}$ mentega, 2 ram telur, $4 \mathrm{~kg}$ gula pasir. Setiap memproduksi roti sisir memerlukan bahan $5 \mathrm{~kg}$ tepung terigu, $4 \mathrm{~kg}$ mentega, 4 ram telur, $5 \mathrm{~kg}$ gula pasir. Pabrik menyediakan $40 \mathrm{~kg}$ tepung terigu, 20 ram telur, $10 \mathrm{~kg}$ mentega, $40 \mathrm{~kg}$ gula pasir. Keuntungan produk roti tawar sebesar Rp.30.000.000,-/bln. Produk roti manis sebesar Rp.40.000.000,-/bln. Produk roti sisir sebesar Rp.20.000.000,-/bln. Berapa jumlah roti yang akan diproduksi agar memperoleh keuntungan maksimum? Awalnya harus dilakukan penentuan variabel.

$$
\begin{aligned}
& \mathrm{X}_{1}=\text { Roti tawar } \\
& \mathrm{X}_{2}=\text { Roti manis } \\
& \mathrm{X}_{3}=\text { Roti sisir }
\end{aligned}
$$

Penentuan fungsi kendala:
1) $10 X_{1}+4 X_{2}+5 X_{3} \leq 40$
2) $2 X_{1}+2 X_{2}+4 X_{3} \leq 10$
3) $5 X_{1}+2 X_{2}+4 X_{3} \leq 20$
4) $10 X_{1}+4 X_{2}+5 X_{3} \leq 40$

Penentuan fungsi tujuan:

$\mathrm{Zmax}=30 \mathrm{X}_{1}+40 \mathrm{X}_{2}+20 \mathrm{X}_{3}$

Proses penyelesaian masalah: 
Mengubah fungsi tujuan dan fungsi kendala.

Fungsi tujuan:

$\mathrm{Z}_{\max }=30 \mathrm{X}_{1}+40 \mathrm{X}_{2}+20 \mathrm{X}_{3}$ menjadi $\mathrm{Z}-30 \mathrm{X}_{1}-$ $40 \mathrm{X}_{2}-20 \mathrm{X}_{3}$

Fungsi kendala:

1) $10 X_{1}+4 X_{2}+5 X_{3} \leq 40$ menjadi $10 X_{1}+4 X_{2}$

$+5 \mathrm{X}_{3}+\mathrm{X}_{4}=40$

2) $2 X_{1}+2 X_{2}+4 X_{3} \leq 10$ menjadi $2 X_{1}+2 X_{2}+$ $4 \mathrm{X}_{3}+\mathrm{X}_{5}=10$

3) $5 X_{1}+2 X_{2}+4 X_{3} \leq 20$ menjadi $5 X_{1}+2 X_{2}+$ $4 \mathrm{X}_{3}+\mathrm{X}_{6}=20$

4) $10 X_{1}+4 X_{2}+5 X_{3} \leq 40$ menjadi $10 X_{1}+4 X_{2}$ $+5 \mathrm{X}_{3}+\mathrm{X}_{7}=40$

Hasil perubahan dimasukkan ke dalam tabel Formulasi (lihat Tabel 1).

Tabel 1. Formulasi

\begin{tabular}{lllllllllll}
\hline Var & $\mathrm{Z}$ & $\mathrm{X}_{1}$ & $\mathrm{X}_{2}$ & $\mathrm{X}_{3}$ & $\mathrm{X}_{4}$ & $\mathrm{X}_{5}$ & $\mathrm{X}_{6}$ & $\mathrm{X}_{7}$ & $\mathrm{NK}$ & Index \\
\hline $\mathrm{Z}$ & 1 & - & - & - & 0 & 0 & 0 & 0 & 0 & \\
& & 30 & 40 & 20 & & & & & & \\
$\mathrm{X}_{4}$ & 0 & 10 & 4 & 5 & 1 & 0 & 0 & 0 & 40 & \\
$\mathrm{X}_{5}$ & 0 & 2 & 2 & 4 & 0 & 1 & 0 & 0 & 10 & \\
$\mathrm{X}_{6}$ & 0 & 5 & 2 & 4 & 0 & 0 & 1 & 0 & 20 & \\
$\mathrm{X}_{7}$ & 0 & 10 & 4 & 5 & 0 & 0 & 0 & 1 & 40 & \\
\hline
\end{tabular}

Berikutnya adalah memilih kolom kunci dan memasukannya ke dalam tabel (lihat Tabel 2).

Tabel 2. Kolom Kunci

\begin{tabular}{lllllllllll}
\hline Var & $\mathrm{Z}$ & $\mathrm{X}_{1}$ & $\mathrm{X}_{2}$ & $\mathrm{X}_{3}$ & $\mathrm{X}_{4}$ & $\mathrm{X}_{5}$ & $\mathrm{X}_{6}$ & $\mathrm{X}_{7}$ & $\mathrm{NK}$ & Index \\
\hline $\mathrm{Z}$ & 1 & - & - & - & 0 & 0 & 0 & 0 & 0 & \\
& & 30 & 40 & 20 & & & & & & \\
$\mathrm{X}_{4}$ & 0 & 10 & 4 & 5 & 1 & 0 & 0 & 0 & 40 & \\
$\mathrm{X}_{5}$ & 0 & 2 & 2 & 4 & 0 & 1 & 0 & 0 & 10 & \\
$\mathrm{X}_{6}$ & 0 & 5 & 2 & 4 & 0 & 0 & 1 & 0 & 20 & \\
$\mathrm{X}_{7}$ & 0 & 10 & 4 & 5 & 0 & 0 & 0 & 1 & 40 & \\
\hline
\end{tabular}

$\mathrm{X}_{2}$ adalah kolom kunci

Setelah memilih kolom kunci, langkah selanjutnya yaitu memilih baris kunci dan menghitung index (lihat Tabel 3).

Tabel 3. Baris Kunci

\begin{tabular}{|c|c|c|c|c|c|c|c|c|c|c|}
\hline Var & $Z$ & $\mathrm{X}_{1}$ & $\mathrm{X}_{2}$ & $\mathrm{X}_{3}$ & $\mathrm{X}_{4}$ & $\mathrm{X}_{5}$ & $\mathrm{X}_{6}$ & $\mathrm{X}_{7}$ & NK & Index \\
\hline$Z$ & 1 & - & - & - & 0 & 0 & 0 & 0 & 0 & \\
\hline & & 30 & 40 & 20 & & & & & & \\
\hline $\mathrm{X}_{4}$ & 0 & 10 & 4 & 5 & 1 & 0 & 0 & 0 & 40 & $\begin{array}{l}40 / 2 \\
=20\end{array}$ \\
\hline $\mathrm{X}_{5}$ & 0 & 2 & 2 & 4 & 0 & 1 & 0 & 0 & 10 & $\begin{array}{l}10 / 2 \\
=5\end{array}$ \\
\hline $\mathrm{X}_{6}$ & 0 & 5 & 2 & 4 & 0 & 0 & 1 & 0 & 20 & $\begin{array}{l}20 / 2 \\
=10\end{array}$ \\
\hline $\mathrm{X}_{7}$ & 0 & 10 & 4 & 5 & 0 & 0 & 0 & 1 & 40 & $\begin{array}{l}40 / 2 \\
=20\end{array}$ \\
\hline
\end{tabular}

$\mathrm{X}_{2}$ adalah kolom kunci

$\mathrm{X}_{5}$ adalah baris kunci
Mengubah nilai-nilai baris kunci (lihat Tabel 4).

Tabel 4. Perubahan Nilai Baris Kunci

\begin{tabular}{lllllllllll}
\hline Var & $\mathrm{Z}$ & $\mathrm{X}_{1}$ & $\mathrm{X}_{2}$ & $\mathrm{X}_{3}$ & $\mathrm{X}_{4}$ & $\mathrm{X}_{5}$ & $\mathrm{X}_{6}$ & $\mathrm{X}_{7}$ & $\mathrm{NK}$ & Index \\
\hline $\mathrm{Z}$ & 1 & - & - & - & 0 & 0 & 0 & 0 & 0 & \\
& & 30 & 40 & 20 & & & & & & \\
$\mathrm{X}_{4}$ & 0 & 10 & 4 & 5 & 1 & 0 & 0 & 0 & 40 & 20 \\
$\mathrm{X}_{5}$ & 0 & 1 & 1 & 2 & 0 & $1 / 2$ & 0 & 0 & 5 & 5 \\
$\mathrm{X}_{6}$ & 0 & 5 & 2 & 4 & 0 & 0 & 1 & 0 & 20 & 10 \\
$\mathrm{X}_{7}$ & 0 & 10 & 4 & 5 & 0 & 0 & 0 & 1 & 40 & 20 \\
\hline
\end{tabular}

Mengubah nilai-nilai selain baris kunci sehingga nilai-nilai kolom kunci (selain baris kunci) $=0$. Kemudian hasilnya dimasukan ke dalam tabel (lihat Tabel 5).

Baris Z

Baris Lama $\quad\left[\begin{array}{cccccccc}-30 & -40 & -20 & 0 & 0 & 0 & 0 & 0\end{array}\right]$

NBBK $\left.\begin{array}{rccccccc}-40[1 & 1 & 2 & 0 & 1 / 2 & 0 & 0 & 5\end{array}\right]-$

Baris Baru

$\left[\begin{array}{llllllll}10 & 4 & 5 & 1 & 0 & 0 & 0 & 40\end{array}\right]$

Baris Lama $4\left[\begin{array}{llllllll}1 & 1 & 2 & 0 & 1 / 2 & 0 & 0 & 5\end{array}\right]$

NBBK

Baris Baru

$\begin{array}{lllllllll}6 & 0 & -3 & 1 & -2 & 0 & 0 & 20\end{array}$

Baris $\mathrm{X}_{6}$

Baris Lama

NBBK

Baris Baru

$\left[\begin{array}{llllllll}5 & 2 & 4 & 0 & 0 & 1 & 0 & 20\end{array}\right]$

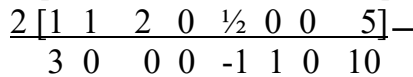

Baris $\mathrm{X}_{7}$

Baris Lama

NBBK

Baris Baru

Tabel 5. Hasil Optimasi

\begin{tabular}{lllllllllll}
\hline Var & $\mathrm{Z}$ & $\mathrm{X}_{1}$ & $\mathrm{X}_{2}$ & $\mathrm{X}_{3}$ & $\mathrm{X}_{4}$ & $\mathrm{X}_{5}$ & $\mathrm{X}_{6}$ & $\mathrm{X}_{7}$ & $\mathrm{NK}$ & Index \\
\hline $\mathrm{Z}$ & 1 & 10 & 0 & 60 & 0 & 20 & 0 & 0 & 200 & \\
$\mathrm{X}_{4}$ & 0 & 6 & 0 & -3 & 1 & -2 & 0 & 0 & 40 & \\
$\mathrm{X}_{5}$ & 0 & 1 & 1 & 2 & 0 & 0.5 & 0 & 0 & 10 & \\
$\mathrm{X}_{6}$ & 0 & 3 & 0 & 0 & 0 & -1 & 1 & 0 & 20 & \\
$\mathrm{X}_{7}$ & 0 & 6 & 0 & 3 & 0 & -2 & 0 & 1 & 40 & \\
\hline
\end{tabular}

Hasil optimasi yang ditampilkan pada Tabel 5 menunjukan bahwa baris $\mathrm{Z}$ tidak lagi memiliki nilai negatif. Hal ini memberikan arti bahwa hasil perhitungan sudah selesai, sehingga hasil yang diperoleh sudah optimal atau telah mendapatkan solusi dari pemecahan masalah pabrik Dani Bakery. Berdasarkan kondisi saat ini, maka keuntungan maksimum yang diperoleh tiap bulan adalah sebesar Rp.200.000.000,- (dua juta rupiah). 
Hasil perhitungan yang diperoleh dapat diuji menggunakan software POM-QM untuk lebih meningkatkan keakuratannya.

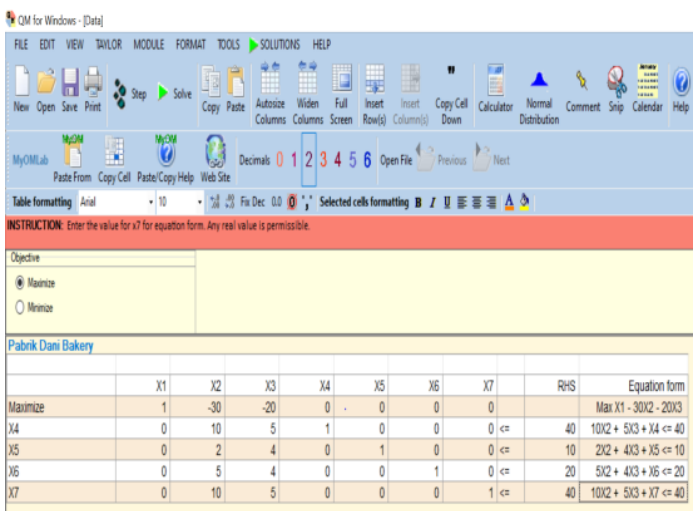

Gambar 3. Tampilan Input Data Formulasi

Setelah melakukan input data formulasi (lihat Gambar 3), kemudian klik tombol solve dan pilih menu Iterations, maka hasil iterasi yang diperoleh akan muncul (lihat Gambar 4).

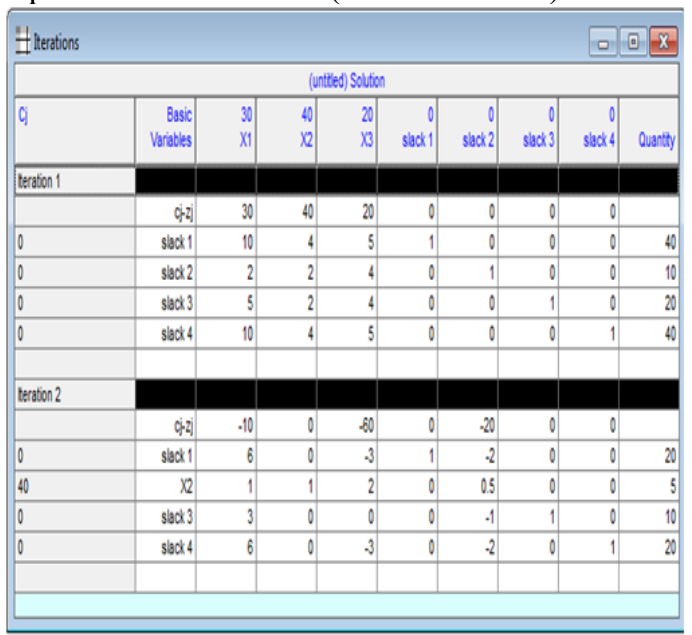

Gambar 4. Hasil Iterations

Sedangkan untuk hasil akhir atau Solutions list dapat dilihat pada Gambar 5.

\begin{tabular}{|c|c|c|c|c|c|c|}
\hline \multicolumn{5}{|c|}{ Wy Linerer Programming Results } & \multicolumn{2}{|c|}{$00 x$} \\
\hline \multicolumn{7}{|c|}{ (unterter) Solvion } \\
\hline & $x_{11}$ & 12 & $x 3$ & & RHS & Oual \\
\hline Haxinze & 30 & 40 & 20 & & & \\
\hline Constrant1 & 10 & 4 & 5 & $\Leftrightarrow$ & 40 & 0 \\
\hline Constrant2 & 2 & 2 & 4 & $\Leftrightarrow$ & 10 & 20 \\
\hline Constrant3 & 5 & 2 & 4 & $\Leftrightarrow$ & 20 & 0 \\
\hline Constrant 4 & 10 & 4 & 5 & $\Leftrightarrow$ & 40 & 0 \\
\hline Soution.) & 0 & 5 & 0 & & 200 & \\
\hline
\end{tabular}

Gambar 5. Tampilan Solution list

Hasil pengujian PL dengan menggunakan software POM-QM yaitu pabrik Dani Bakery memperoleh keuntungan maksimal sebesar Rp.200.000.000,- per produksi roti setiap bulannya. Hasil ini sama dengan hasil perhitungan manual, sehingga tidak terjadi kekeliruan dalam proses perhitungan. Hasil yang diperoleh ini dapat digunakan oleh pimpinan pabrik Dani Bakery sebagai acuan dalam pengambilan keputusan.

\section{Kesimpulan}

Berbagai kesimpulan yang dapat ditarik dari hasil penelitian, yaitu:

1) PL dengan metode Simpleks dapat membantu menyelesaikan masalah yang dihadapi oleh pabrik Dani Bakery. Karena metode ini memberikan solusi terbaik yang dapat digunakan sebagai acuan dalam pengambilan keputusan.

2) Hasil perhitungan metode Simpleks baik manual maupun pengujian dengan menggunakan software POM-QM mendapatkan keuntungan sebesar Rp.200.000.000,- per produksi roti setiap bulannya.

3) Efektif serta efisien dapat dicapai oleh pabrik Dani Bakery dalam pengelolaan usaha dengan memanfaatkan TI yang ada.

\section{Ucapan Terima Kasih}

Terima kasih yang sebesar-besarnya disampaikan kepada pihak pabrik Dani Bakery, serta Program Studi Sistem Informasi Universitas Victory Sorong atas segala sumbangsinya selama penelitian ini berlangsung.

\section{Daftar Pustaka}

[1] M. S. Rumetna, T. N. Lina, and J. E. 
Lopulalan, "A knowledge management system conceptual model for the sorong COVID-19 task force," Int. J. Informatics Vis., vol. 4, no. 4, pp. 195200, 2020, doi: 10.30630/joiv.4.4.418.

[2] M. S. Rumetna and I. Sembiring, "PEMANFAATAN CLOUD COMPUTING BAGI USAHA KECIL MENENGAH (UKM)," in Prosiding Seminar Nasional Geotik, 2017, no. ISSN:2580-8796, pp. 1-9.

[3] M. S. Rumetna, "Pemanfaatan Cloud Computing Pada Dunia Bisnis: Studi Literatur," J. Teknol. Inf. dan Ilmu Komput., vol. 5, no. 3, pp. 305-314, 2018, doi: 10.25126/jtiik.201853595.

[4] M. S. Rumetna, "Audit Lingkungan Dan Pengendalian Teknologi Informasi Pada Pt. Xyz," Simetris J. Tek. Mesin, Elektro dan Ilmu Komput., vol. 9, no. 2, pp. 753768, 2018, doi: 10.24176/simet.v9i2.2294.

[5] T. N. Lina et al., "SISTEM INFORMASI E-ARSIP BERBASIS WEB (STUDI KASUS : PT HALEYORA POWERINDO CABANG SORONG)," J. Jendela Ilmu, vol. 1, no. 1, pp. 1-5, 2020.

[6] M. S. Rumetna, E. E. Renny, and T. N. Lina, "Designing an Information System for Inventory Forecasting," Int. J. Adv. Data Inf. Syst., vol. 1, no. 2, pp. 80-88, 2020, doi: 10.25008/ijadis.v1i2.187.

[7] E. N. Ekwonwune and D. C. Edebatu, "Application of Linear Programming Algorithm in the Optimization of Financial Portfolio of Golden Guinea Breweries Plc, Nigeria," Open J. Model. Simul., vol. 04, no. 03, pp. 93-101, 2016, doi: 10.4236/ojmsi.2016.43008.

[8] N. P. \& Akpan and I. A. Iwok, "Application of Linear Programming for Optimal Use of Raw Materials in Bakery," Int. J. Math. Stat. Invent. www.ijmsi.org, vol. 4, no. 8, pp. 51-57, 2016, [Online]. Available: www.ijmsi.org.

[9] T. Chandra, "Penerapan Algoritma Simpleks dalam Aplikasi Penyelesaian Masalah Program Linier," TIMES, vol.
IV, no. 1, pp. 18-21, 2015.

[10] T. Sriwidadi and E. Agustina, "ANALISIS OPTIMALISASI PRODUKSI DENGAN LINEAR PROGRAMMING MELALUI METODE SIMPLEKS," Binus Bus. Rev., vol. 4, no. 2, pp. 725-741, 2013.

[11] L. Sarmin et al., "PENERAPAN METODE SIMPLEKS UNTUK MENGHITUNG KEUNTUNGAN MAKSIMUM PADA PENGRAJIN GELANG BESI PUTIH DI PASAR REMU SORONG," J. KUADAS, vol. 1, no. 2, pp. 1-7, 2018.

[12] Z. Nasution et al., "PENERAPAN METODE SIMPLEKS UNTUK MENGANALISA PERSAMAAN LINIER DALAM MENGHITUNG KEUNTUNGAN MAKSIMUM," J. Ris. Komput., vol. 3, no. 4, pp. 42-48, 2016.

[13] M. S. Rumetna, T. N. Lina, L. Simarmata, L. Parabang, A. Joseph, and Y. Batfin, "Pemanfaatan POM-QM Untuk Menghitung Keuntungan Maksimum UKM Aneka Cipta Rasa (ACR) Menggunakan Metode Simpleks," in GEOTIK, 2019, pp. 12-22.

[14] M. Rumetna, Supriyanto et al., "PENERAPAN METODE SIMPLEKS UNTUK MENGHASILKAN KEUNTUNGAN MAKSIMUM PADA PENJUAL BUAH PINANG," $J$. Dedication To Papua Community2, vol. 2, no. 1, pp. 75-86, 2019.

[15] N. Luh and G. Pivin, "Penerapan Metode Simpleks Untuk Optimalisasi Produksi Pada UKM Gerabah," in Konferensi Nasional Sistem \& Informatika, 2017, vol. 3, pp. 208-213.

[16] D. K. Nadar, "Some Applications of Simplex Method," Int. J. Eng. Res. Rev., vol. 24, no. 1, pp. 60-63, 2016, doi: 10.5958/2395-3381.2015.00018.0.

[17] R. Ong et al., "Maksimalisasi Keuntungan Pada Usaha Dagang Martabak Sucipto Menggunakan Metode Simpleks Dan POM-QM," Ris. Komput., vol. 6, no. 4, pp. 434-441, 2019.

[18] V. Ngamelubun et al., "Optimalisasi Keuntungan Menggunakan Metode 
Simpleks Pada Produksi Batu Tela," Ris. Komput., vol. 6, no. 5, pp. 484-491, 2019.

[19] M. S. Rumetna et al., "Mengoptimalilasi keterbatasan sumber daya untuk memaksimalkan keuntungan penjualan es kelapa muda menggunakan metode simpleks dan software pom-qm," Pengabdi. Masy., vol. 02, no. 02, pp. 136-149, 2019.

[20] M. S. Rumetna et al., "Optimasi Pendapatan Pembuatan Spanduk dan Baliho Menggunakan Metode Simpleks ( Studi Kasus: Usaha Percetakan Shiau Printing )," J. Ris. Komput., vol. 7, no. 2, pp. 278-284, 2020, doi: 10.30865/jurikom.v7i2.1922.

[21] G. B. Dantzig, "Linear programming," Oper. Res., vol. 50, no. 1, pp. 42-47, 2002.

[22] M. S. Rumetna, T. N. Lina, T. Aponno, A. Palisoa, and F. Singgir, "Penerapan Metode Simpleks Dan Software POMQM Untuk Optimalisasi Hasil Penjualan Pentolan Bakso," Ilm. Manaj. Inform. dan Komput., vol. 02, no. 03, pp. 143149, 2018.

[23] M. S. Rumetna, T. N. Lina, L. R. Tauran, T. Patty, A. Malak, and K. Yawan, "Penerapan Metode Simpleks pada Usaha Dagang Bintang Tiurma," $J$. Innov. Inf. Technol. Appl., vol. 2, no. 01, pp. 28-36, 2020.

[24] M. S. Rumetna et al., "MENGHITUNG KEUNTUNGAN MAKSIMAL DARI PENJUALAN ROTI ABON GULUNG DENGAN MENGGUNAKAN METODE SIMPLEKS DAN SOFTWARE POM-QM," J. Jendela Ilmu, vol. 1, no. 1, pp. 6-12, 2020.

[25] T. N. Lina, B. S. Marlissa, M. S. Rumetna, and J. E. Lopulalan, "Penerapan Metode Simpleks Untuk Meningkatkan Keuntungan Produksi," Ris. Komput., vol. 7, no. 3, pp. 459-468, 2020, doi: 10.30865/jurikom.v7i3.2204.

[26] Y. Isabella, H. Cahyadi, and R. Respati, "PEMILIHAN RUTE TERPENDEK DENGAN MENGGUNAKAN SOFTWARE POM QM FOR
WINDOWS 3 (STUDI KASUS JALAN SANGGA BUANA 2- UNIVERSITAS MUHAMMADIYAH

PALANGKARAYA)," Media Ilm. Tek. Sipil, vol. 4, no. 1, pp. 124-132, 2016.

T. N. Lina et al., "PENERAPAN METODE SIMPLEKS DALAM OPTIMALISASI KEUNTUNGAN HASIL PRODUKSI LEMON CINA DAN DAUN JERUK PURUT," Elektro Luceat, vol. 6, no. 1, 2020.

M. S. Rumetna et al., "OPTIMALISASI PENJUALAN NOKEN KULIT KAYU MENGGUNAKAN METODE SIMPLEKS DAN SOFTWARE POMQM," Comput. Based Inf. Syst. J., vol. 08, no. 02, pp. 37-45, 2020.

M. S. Rumetna et al.,
"PENDAMPINGAN
PELATIHAN PENERAPAN METODE SIMPLEKS PADA USAHA DAGANG BINTANG TIURMA," J. Abdimas Bina Bangsa, vol. 01, no. 02, pp. 205-214, 2020.

M. S. Rumetna, D. Manongga, and A. Iriani, "PENERAPAN KNOWLEDGE CAPTURE UNTUK PROMOSI FAKULTAS MENGGUNAKAN SOFT SYSTEM METHODOLOGY ( SSM ) ( STUDI KASUS : FAKULTAS TEKNIK , UNIVERSITAS VICTORY SORONG )," in Prosiding Seminar Nasional Geotik, 2017, pp. 106-116.

T. N. Lina, D. Manongga, and A. Iriani, "PENERAPAN FRAMEWORK KNOWLEDGE MANAGEMENT PADA UKM KULIT PARI YOGYAKARTA," in Seminar Nasional GEOTIK, 2017, pp. 139-145.

M. S. Rumetna, M. Pieter, and M. Manurung, "APLIKASI PENGENALAN KARAKTER ALFANUMERIK MENGGUNAKAN ALGORITMA HAMMING DISTANCE," Pros. SNATIF, no. 4, pp. 77-84, 2017, [Online]. Available: https://media.neliti.com/media/publicatio ns/173678-ID-aplikasi-pengenalankarakter-alfanumerik.pdf. M. S. Rumetna, E. Sediyono, and K. D. 
Hartomo, “Analisis Perubahan Tata Guna Lahan di Kabupaten Bantul Menggunakan Metode Global Moran's I," J. Buana Inform., vol. 8, no. 4, pp. 225-234, 2017, doi: 10.24002/jbi.v8i4.1446.

[34] T. N. Lina and M. S. Rumetna, "Analysis of Land Use Change in Bantul Regency Using Geoprocessing Technique," in International Conference of Computer Science and Engineering Technology(ICCSET), 2018, pp. 506512, doi: 10.4108/eai.24-102018.2280499.

[35] M. S. Rumetna, "PEMANFAATAN SISTEM INFORMASI GEOGRAFI UNTUK DETEKSI DAERAH RAWAN
LONGSOR DI KECAMATAN SIDOMUKTI, SALATIGA," KUADAS, vol. 1, no. 1, 2018.

[36] M. S. Rumetna, T. N. Lina, and A. B. Santoso, "RANCANG BANGUN APLIKASI KOPERASI SIMPAN PINJAM MENGGUNAKAN METODE RESEARCH AND DEVELOPMENT," Tek. Mesin, Elektro dan Ilmu Komput., vol. 11, no. 1, pp. 119-128, 2020.

[37] M. S. Rumetna and T. N. Lina, "Sistem Informasi Kampung Wisata Arborek Dengan Metode Waterfall," Informatics Educ. Prof., vol. 5, no. 1, pp. 31-40, 2020. 